\title{
Exploring the Effects of Student Course Withdrawals on Time to Graduation
}

\section{Dr. Gillian M. Nicholls, University of Alabama, Huntsville}

Gillian Nicholls is an assistant professor of Industrial \& Systems Engineering \& Engineering Management and a 2009-2010 Gray Faculty Fellow at the University of Alabama in Huntsville. Her research interests are in applying statistical analysis and optimization to supply chain management, transportation management, and engineering education. She holds the B.S. in Industrial Engineering (Lehigh University), Masters in Business Administration (Penn State University), M.S. in Industrial Engineering (University of Pittsburgh.), and Ph.D. in Industrial Engineering (University of Pittsburgh). Address: N149 Technology Hall, The University of Alabama in Huntsville, Huntsville, AL 35899; telephone (+1) 256.824.6637; fax: (+1) 256.824.6733; e-mail: gillian.nicholls@uah.edu.

\section{Dr. Rhonda Kay Gaede, University of Alabama, Huntsville}

Rhonda Gaede received a BS in Electrical Engineering from Southern Methodist University and an MS and $\mathrm{PhD}$ in Electrical Engineering from The University of Texas at Austin. She worked as a product engineer for Motorola and as a staff engineer for IBM. She is currently an Associate Professor at The University of Alabama in Huntsville where she teaches computer architecture, logic design and hardware design and verification using VHDL and SystemVerilog. Research interests include factors contributing to academic success, hardware verification, and computer architecture and performance. Address:211 Engineering Buildingl, The University of Alabama in Huntsville, Huntsville, AL 35899; telephone (+1) 256.824.6573; fax: (+1) 256.824.6803; e-mail: rhonda.gaede@uah.edu. 


\title{
Exploring the Effects of Student Course Withdrawals on Time to Graduation
}

\begin{abstract}
Persistence and retention of undergraduate students remain serious concerns in engineering education. The first two years in which students are enrolled in the gateway math, science, and engineering courses are a period when many students chose to switch out. Universities are under increasing pressure to educate students more effectively in terms of cost and time. This is particularly true for Colleges of Engineering which have seen the time to graduate with a bachelor's degree increase over time as the material judged to be important has expanded; more students begin college less academically prepared to advance steadily; and students are more mobile often transferring between schools or taking classes part time while working. The frequency of students withdrawing from classes has also increased over time. The academic policies governing course withdrawals can affect these trends.

This research paper discusses the effects on time to graduation of undergraduate engineering student patterns in course withdrawals. Engineering student course enrollment data from Fall 2003 through Summer 2013 at the University of Alabama in Huntsville (UAH) has been collected to analyze patterns in the core math, science, and engineering classes. Other variables including gender, race/ethnicity, age, prior GPA, transfer student status, and number of part time semesters have also been collected. This time period was chosen to extend the sample across two academic policies. From 1999-2009 almost all 100 and 200 level classes were graded on an A, B, C, D, and No Credit (NC) basis with NC grades being excluded from GPA calculations. This had the unfortunate effect of enabling students that were not making good academic progress to remain enrolled without triggering any academic interventions. The policy was abolished in 2009, but students are still allowed unlimited course withdrawals that also do not affect GPA calculations. An initiative within the College of Engineering focuses on monitoring and improving students' academic progress to ensure that all undergraduates are successfully completing at least $66 \%$ of all credit hours attempted. Concerns have been raised about the unlimited withdrawal policy; particularly in light of rising tuition, limits on financial aid, and the growing national problem of student loan debt. Specifically, there is concern that utilizing the option of unlimited withdrawals may lead students to take a longer time to graduate. The research hypothesis is that a greater number of course withdrawals is associated with a longer time to graduation. While this hypothesis is intuitively obvious, it is important to analyze the data to formally prove/disprove it and to determine if there is a critical number of withdrawals students should not exceed.
\end{abstract}

\subsection{Introduction}

The College of Engineering at UAH is concerned about the academic progression of engineering students. The number of students entering the engineering pipeline, the number of students that depart the engineering track, and the length of time it takes those remaining to complete their degree are of enormous importance to the university, the students, prospective employers, and society as a whole. Analysis of the future demands for STEM graduates indicates that more must be done to supply those future demands and one of the most budgetary conscious ways to address the problem is through better retention and persistence of students that enter the pipeline $^{[1]}$. Within this university, an initiative has been undertaken by the College of 
Engineering to closely monitor all undergraduate engineering students to identify students that are showing signs of difficulty in progressing academically and support stronger academic performance. The minimum level of academic progression expected is successful completion of at least $66 \%$ of the credit hours attempted with a D or better. Students that drop below this level of progression are flagged for outreach. Separately, efforts are underway to better support students during their coursework.

Support efforts include identifying courses that have historically been difficult for many engineering students and recruiting capable undergraduate students that have already successfully completed them to conduct "Peer Assisted Study Sessions” or PASS. Such PASS sections offer students registered in the class a more structured environment in which to work on homework, review challenging material, and ask questions in addition to obtaining assistance from the instructor, a teaching assistant, or the university tutoring center. The University's Student Success Center leadership has analyzed the grades of students in PASS sections and indicated that students who consistently utilize the PASS resources complete their courses earning an average of one grade level higher than those who do not use the resources.

Another initiative is examining academic policies to determine whether they fulfill their intent of aiding students rather than unintentionally leading to other problems. One policy under review governs students' ability to withdraw from a class. Currently, students are able to withdraw from a course for any reason until the end of the $10^{\text {th }}$ week of a 14-week semester. A withdrawal appears on a student's transcript as a "W", but it does not factor into the calculation of the Grade Point Average (GPA). No financial refund is available to students that withdraw from a class after the first two weeks of the semester when the drop period ends. Students that experienced difficulty with several classes may withdraw from all or some of their classes during that semester. Students normally withdraw from a single class if they are not performing well in order to prevent their final course grade from adversely affecting their GPA. In one extreme case at the University, a student enrolled in the same class 18 times with a combination of 17 withdrawals, NC's and F's, before successfully completing it with a B.

Withdrawing from one or more classes may have some serious drawbacks for students. They lose the economic investment in the course, their cost to complete the degree may rise correspondingly, their pattern of course-taking may be disrupted as pre-requisite courses must be retaken before successor classes, and the appearance of one or more "W's" on a transcript may be off-putting to prospective employers. The new Dean of Students examined the policy after being appointed to the position and expressed concern that allowing students unlimited withdrawals was not ultimately benefiting students. Suggested changes to the policy of unlimited withdrawals have been discussed, but none has been approved to date. The suggested changes included placing a cap on the number of withdrawals allowed overall or a cap on the number of withdrawals for a single course. This study was undertaken to examine the data and determine whether evidence supported changing the current course withdrawal policy.

\subsection{Literature Review}

Prior research by Seymour and Hewitt has found that the first two years in which students are enrolled in the gateway math, science, and engineering courses are a period when many students 
choose to switch out ${ }^{[2]}$. Universities are under increasing pressure to educate students more effectively in terms of cost and time ${ }^{[3,4]}$. The financial cost of course-taking to complete a degree is a significant expense for students. This is particularly true for Colleges of Engineering which have seen the time to graduate with a bachelor's degree increase over time as the material judged to be important has expanded, more students begin college less academically prepared to advance steadily; and students are more mobile often transferring between schools or taking classes part time while working. The frequency of students withdrawing from classes has also increased over time ${ }^{[5-8]}$. Withdrawing from a course can slow down academic progression and increase the risk of dropping out of school overall from poor achievement ${ }^{[9]}$.

There are many reasons why students withdraw from one or more classes. External factors include conflicts between school and a job or financial problems ${ }^{[10-14]}$. Family obligations, travel for work, and problems with poor health for either the student or a family member are other significant external factors ${ }^{[15]}$. Students may find their expectations of what the course would entail differ from the reality ${ }^{[16]}$. Problems with a heavy courseload, unsatisfactory teaching, or disenchantment with the course material are also cited as factors in course withdrawal decisions $[17,18]$. Gender and transfer student status have shown value as predictors of course withdrawal with females and transfer students having a higher risk of course withdrawal ${ }^{[19]}$. Students considering course withdrawal have been found to frequently seek advice from personal contacts rather than academic advisors ${ }^{[20]}$.

The time to graduation with an undergraduate college degree has been examined to identify trends in the length of time and factors that are predictive of an extended time period. Chimka, Reed-Rhoads, and Barker reported that student gender and standardized test scores in math and science such as the SAT math score and ACT science score were strong predictors of time to graduation ${ }^{[21]}$. Male students that reported ACT scores but not SAT scores were more likely to achieve graduation with an engineering degree if they earned a higher science ACT score. Among students that reported SAT but not ACT scores, female students and those with higher SAT math scores were more likely to achieve a bachelors degree in engineering. Subsequent study of engineering students by Chimka and Lowe utilizing Cox proportional hazards models identified an interesting interaction between the English and science ACT scores. Male engineering students having higher English standardized test scores were found to persist to graduation at a higher rate than counterparts with lower English test scores ${ }^{[22]}$. Caroni also found female students were more likely to complete their engineering degrees, but that overall only $27 \%$ of students admitted in a particular cohort graduated within 5 years ${ }^{[23]}$. Min, et al. identified SAT math scores as a stronger predictor of departing engineering than SAT verbal scores and showed that bands of SAT scores had differing hazard rates ${ }^{[24]}$. They also found that white and female engineering students were likelier to leave engineering earlier in the degree program than their counterparts. The period of greatest out-migration was the third semester.

The examination of attrition rates in engineering is made more complex when students are taking class on a part time basis and especially via distance learning. The time to graduate with a bachelors degree in engineering can expand from 4 to 8 years ${ }^{[25]}$. As more non-traditional students seek college degrees while continuing to work full time, the job of educating engineers becomes more challenging. Many factors affect the likelihood of students graduating, including course offerings by semester, the time of day courses are offered, and the structure of the 
program $^{[26]}$. Formally smoothing the pathways into engineering including rationalizing prerequisites to permit easier in-migration from other degree programs was suggested as one way to increase the numbers of engineering graduates ${ }^{[27]}$.

The financial costs of course withdrawal and potentially extending the time to graduation are notable. A single course withdrawal that does not lead to a delay in graduation may cost the student nothing if the credit hours to retake the class do not exceed the maximum credit load before additional tuition is charged. However, if the course withdrawal leads to a difficult registration schedule that strains an already stressed student's performance into doing badly in other courses, the effect can snowball. A delay in graduation can lead to incurring additional registration and tuition costs, potentially incurring additional living expenses, and delays the time at which the prospective graduate begins earning a salary as an employed engineer. The financial impacts are further increased if a student is financing the cost of attending college with student loans ${ }^{[28,29]}$. The total volume of student loan debt in the United States as of the fourth quarter of 2013 has surpassed $\$ 1$ trillion $^{[30]}$. The percentage of student loans that have slipped into the $90+$ day delinquency status has risen to $11.8 \%$. This has sobering implications for the economic futures of students that leave school with or without a degree but carrying a student loan burden.

Overall, the prior literature reports that time to graduation can be predictively modeled using gender, race/ethnicity, part time student status, and standardized test scores in math, science, and English. The instances of course withdrawals can be associated with gender, transfer student status, personal issues, professional obligations, and disengagement from the material; particularly within the first two years of matriculation. These findings lead to the selection of general demographic variables, student status variables, prior academic performance variables, and instances of course withdrawals from the early gateway coursework for this analysis of time to graduation. This study attempts to formally test for an association between the instances of course withdrawals and the time to graduation.

\subsection{Research Design}

\subsection{Motivation}

The purpose of this study was to identify patterns in the course-taking data for engineering undergraduate students that could be used to determine whether the policy of unlimited withdrawals should be changed to limit the maximum number. While the data is drawn from engineering undergraduates at a single university, the approach is generalizable for adoption at other institutions or by other disciplines. It is theorized that a history of withdrawing from the gateway math and science classes is associated with delays in graduation. If a critical number of course withdrawals can be found, a change to current academic policy may be beneficial. These gateway classes are prescribed in a planned sequence to allow students to scaffold critical new knowledge on top of core concepts learned in earlier classes. Students that have difficulty and withdraw from the core gateway classes risk disrupting the course-taking progression, complicate their ability to register for courses in subsequent semesters, and may require additional time to complete their degree. Identifying these students at an earlier point provides more time to offer supportive interventions and encourage them to consider alternative academic strategies besides withdrawing. The study is envisioned as part of a broader analysis to identify 
students at the greatest risk of an extended time to graduation in order to target interventions that could be offered to aid students and reduce withdrawals.

The university has a significant population of transfer students in engineering who have taken some or all of their first two years of coursework at less expensive community colleges. There is also a sizeable population of part time students that are employed part or full time. This makes Alabama in Huntsville an excellent site at which to examine the phenomena of non-traditional students that is becoming more common throughout academia in the United States.

\subsection{Dataset}

Records for undergraduate engineering students enrolled at UAH from Fall 2003 through Summer 2013 were obtained for each class they took, enabling identification of the number of courses from which they withdrew. This course withdrawal information was associated with the student to test for a relationship between course withdrawals and time to graduation. Since prior research indicates that the period of greatest risk of departing the STEM track is in the first two years, the data was sifted to examine the course withdrawal and success rates for these students in the core math, science, and engineering classes as well as other classes. The dataset contains a total of 39,509 unique course enrollments. Other variables including gender, race/ethnicity, age at matriculation, major, prior grade point average (GPA) at the student's high school or most recent transferring school, transfer status, and number of part time semesters have also been collected.

The 2003-2013 time period was chosen to extend the sample across two academic policies. From 1999-2009 almost all 100 and 200 level classes were graded on an A, B, C, D, and No Credit (NC) basis with NC grades being excluded from GPA calculations. The NC policy was envisioned to encourage students to attempt more challenging coursework without concerns that a lower grade would adversely affect their GPA. Unfortunately, the policy had the effect of enabling students that were not making good academic progress to remain enrolled without triggering any academic interventions. The policy was abolished in 2009, but students are still allowed unlimited course withdrawals that also do not affect GPA calculations.

Each individual engineering student represented in the dataset was categorized either as a transfer student or as a "native" student that first enrolled as a freshman at UAH. Transfer student status is complicated by students that may have dual enrollment in two institutions or take classes during the summer breaks. For this study, transfer student status is defined as having more than 12 credit hours of transfer credit. The total time to graduation for transfer students including their prior studies was not consistently available for each student. For this reason, the time to graduation for transfer students only reflects their time from matriculation to graduation at UAH.

\subsection{Research Hypothesis}

The research hypothesis in this analysis is that the number of instances of a single student withdrawing from a course is positively associated with a longer time to graduation. The null hypothesis is that there is no association between the number of course withdrawals and time to graduation. Other possible factors in examining time to graduation include the number of unsuccessful course completions (D’s, F's, or NC's), gender, race/ethnicity, prior GPA, transfer 
student status, age at matriculation, and part time enrollment. It seems intuitively obvious that withdrawing from classes may lead to a longer time to graduation. However, deciding whether to change academic policy regarding the number of permissible course withdrawals requires testing the data to determine whether there is a critical value. Is there a number of course withdrawals that distinguish between giving students some flexibility to lighten the academic burden in a semester and risking their educational prospects?

Each student's age at first enrollment at UAH was utilized to categorize the individual as a traditional vs. non-traditional age student. The time between first enrollment at UAH and graduation was measured as the time to graduation. Some students were still enrolled as of the latest data collected from Summer 2013 and were excluded from this examination of the data since the event of interest (graduation) was not observed prior to the study's end. Additional data analysis is anticipated on an ongoing basis to address questions about retention and persistence overall. The future analysis will consider outcomes such as students that graduated with an engineering degree, graduated with a different degree, dropped out, etc.

\subsection{Data Analysis}

The dataset was condensed to the records of all students $(2,012)$ that graduated with a bachelors of science in an engineering major between Fall 2003 and Summer 2013. A total of 33 records were excluded from analysis due to obvious Prior GPA data entry errors (5 records) or having an age at matriculation that indicated dual enrollment during high school (28 records). Table 1 and Table 2 summarize the breakdown of the records by gender, race/ethnicity, and transfer student status.

Table 1 B.S. Engineering Graduates 2003-2013 by Gender and Transfer Status

\begin{tabular}{|c|c|c|r|}
\hline \multirow{2}{*}{ Gender } & \multicolumn{2}{|c|}{ Transfer Student Status } & \multirow{2}{*}{ Total } \\
\cline { 2 - 3 } & "Native” Student & Transfer Student & \\
\hline Male & 706 & 889 & 1,595 \\
\hline Female & 175 & 209 & 384 \\
\hline Total & 881 & 1,098 & 1,979 \\
\hline
\end{tabular}

Table 2 B.S. Engineering Graduates 2003-2013 by Gender and Race/Ethnicity

\begin{tabular}{|c|c|c|c|c|c|c|c|c|c|}
\hline \multirow[t]{2}{*}{ Gender } & \multicolumn{8}{|c|}{ Race/Ethnicity } & \multirow[t]{2}{*}{ Total } \\
\hline & Asian & Black & $\begin{array}{l}\text { Hispanic } \\
\text { /Latino }\end{array}$ & $\begin{array}{l}\text { Native } \\
\text { Amer. }\end{array}$ & $\begin{array}{l}\text { Pacific } \\
\text { Islander }\end{array}$ & White & Multi. & $\begin{array}{c}\text { No } \\
\text { Answer }\end{array}$ & \\
\hline Male & 69 & 105 & 32 & 25 & 0 & 1,323 & 5 & 36 & 1,595 \\
\hline Female & 30 & 49 & 13 & 8 & 1 & 278 & 0 & 5 & 384 \\
\hline Total & 99 & 154 & 45 & 33 & 1 & 1,601 & 5 & 41 & 1,979 \\
\hline
\end{tabular}

The variables measuring Time to Graduation, Prior GPA, and Age at Matriculation were also grouped into ranges to create companion ordinal category variables. Since the numbers of students in the underrepresented race/ethnic categories were comparatively small, an additional binary variable indicating majority/minority status was created. Companion categorical variables were also created for the number of course withdrawals. One binary variable was constructed to measure whether a student had 0 course withdrawals or more. A second binary 
variable classified the students as having 0 or 1 course withdrawal vs. 2 or more. A third binary variable classified the students as having $0-2$ course withdrawals vs. 3 or more. Similarly, additional binary variables were created to classify the number of course withdrawals using breakpoints of 4, 5, or 6 course withdrawals. A binary variable was constructed to classify the students as having had significant part time status (6 or more semesters) or not.

A set of $t$-tests for independent samples were used to analyze differences in the mean times to graduation between the groups of students when classified by the binary numbers of course withdrawals. Pearson's Chi-square contingency tables were used to test for independence between the ordinal time to graduation variable and the ordinal Prior GPA variable, the ordinal age range, and the binary Part Time Status variable.

\subsection{Findings}

The research hypothesis that instances of course withdrawals leads to a longer time to graduation was tested with independent samples $t$-tests in an attempt to find a critical value for the number of course withdrawals. The time to graduation in years was tested for students that had 0 vs. more course withdrawals. The students that had no course withdrawals $(\mathrm{M}=4.4252$ years, $\mathrm{SD}=$ 2.9617) tended to graduate in less time than the students that withdrew from at least one course $(\mathrm{M}=5.1421$ years, $\mathrm{SD}=2.5366), t(1977)=-5.712, p<0.00$. The students that had at most 1 course withdrawal $(\mathrm{M}=4.4879$ years, $\mathrm{SD}=2.8350)$ graduated in less time than the students that withdrew from 2 or more classes $(M=5.4771$ years, $\mathrm{SD}=2.5665), t(1977)=-7.005, p<0.00$. The students that had at most 2 course withdrawals $(M=4.5297$ years, $S D=2.7562)$ graduated in less time than the students that withdrew from 3 or more classes $(\mathrm{M}=5.8488$ years, $\mathrm{SD}=$ 2.7652), $t(1977)=-7.913, p<0.00$. Testing of additional binary course withdrawal variables up through 6 or more course withdrawals continued to find statistically significant differences.

Thus the null hypothesis that the number of course withdrawals is not associated with the time to graduation is rejected. As expected, the incidence of course withdrawals is associated with a longer time to graduation. However, there was no apparent critical threshold value for the acceptable number of course withdrawals. Even one withdrawal from a course was significantly associated with a longer time to graduation.

Since previous researchers had found other demographic and prior academic performance variables to be significant in explaining time to graduation, additional tests were conducted with this dataset. Gender vs. time to graduation in years was tested with an independent samples $t-$ test. Male students $(\mathrm{M}=4.7617$ years, $\mathrm{SD}=2.7780)$ compared to female students $(\mathrm{M}=4.6929$ years, $\mathrm{SD}=2.8941$ ) revealed no significant difference, $t(1977)=0.432, p<0.666$. Thus the null hypothesis of no significant difference between the genders on mean time to graduation cannot be rejected.

Transfer student status vs. time to graduation in years was tested with an independent samples $t$ test. Native students $(\mathrm{M}=5.1979$ years, $\mathrm{SD}=1.9795)$ compared to transfer students $(\mathrm{M}=$ 4.3876 years, $\mathrm{SD}=3.2717$ ) revealed a significant difference, $t(1977)=6.463, p<0.00$ with transfer students tending to graduate in less time at UAH. Thus the null hypothesis of no significant difference between transfer and native students on mean time to graduation can be rejected. This result was expected given that transfer students had already completed 
coursework at their prior institution(s). However, it was interesting that the difference in means was less than 1 year.

Minority status vs. time to graduation in years was tested with an independent samples $t$-test. White students $(\mathrm{M}=4.7743$ years, $\mathrm{SD}=2.9164)$ compared to minority status students $(\mathrm{M}=$ 4.6384 years, $\mathrm{SD}=2.2429$ ) found no significant difference, $t(1977)=0.848, p<0.397$. Thus the null hypothesis of no significant difference by race/ethnicity on mean time to graduation cannot be rejected.

Contingency tables were utilized to test for independence between potential categorical factors and the time to graduation when categorized as 0-2 years, 2-4 years, 4-5 years, 5-6 years, 6-7 years, or over 7 years. Prior GPA was categorized as $<2.0,2.0-2.99$, 3.0 -3.49 , and $>3.49$. The Pearson chi-square statistic was 184.632 with 20 degrees of freedom, $p<0.00$. Thus the null hypothesis of independence between Prior GPA and time to graduation can be rejected. Students with a lower incoming GPA tended to take longer to graduate.

Age at matriculation vs. time to graduation was tested and the Pearson chi-square statistic was 562.358 with 25 degrees of freedom, $p<0.00$. Thus the null hypothesis of independence between age at matriculation and time to graduation can be rejected. Students that were older at matriculation tended to take less time to graduate. Part time status vs. time to graduation was tested, and the Pearson chi-square statistic was 286.942 with 5 degrees of freedom, $p<0.00$. Thus the null hypothesis of independence between part time status and time to graduation can be rejected. As expected, students with 6 or more terms of part time enrollment status (taking fewer than 12 credits) tended to take longer to graduate.

Having found that course withdrawals are significant contributors to time to graduation, we looked at gateway course completion as possible targets for intervention. The gateway classes are prerequisites for subsequent coursework and as such, the university requires students to achieve a grade of $\mathrm{C}$ or better. Students that earn a lower grade or withdraw from a gateway course must repeat it later. Gateway courses generally taken in the later years were not examined in this analysis. Remedial coursework in chemistry and calculus was also included in the analysis since they are a necessary prerequisite for many incoming students. Table 3 shows the percentage (number) of student attempts at gateway courses taken by engineering students in their first two years of study that resulted in successfully completing the course with a grade of A, B, or C; unsuccessfully completing the course with a grade of D, F, or NC; or withdrawing from the course. The table has three levels of shading that represent 1 ) the courses with the worst success rates, 2) the courses with middling success rates and 3) the courses with the best success rates. 
Table 3 Gateway Course Data Fall 2003-Summer 2013

\begin{tabular}{|l|c|r|r|r|r|r|}
\hline \multicolumn{1}{|c|}{ Coursework } & $\begin{array}{c}\text { \# of } \\
\text { Records }\end{array}$ & $\begin{array}{c}\text { \% A/B/C } \\
\text { Grades }\end{array}$ & $\begin{array}{c}\text { \% D } \\
\text { Grades }\end{array}$ & $\begin{array}{r}\text { \% F } \\
\text { Grades }\end{array}$ & $\begin{array}{r}\text { \% NC } \\
\text { Grades }\end{array}$ & $\begin{array}{r}\text { \% W } \\
\text { Grades }\end{array}$ \\
\hline Pre-Calculus & 2,878 & $61.86 \%$ & $10.86 \%$ & $14.07 \%$ & $4.02 \%$ & $9.19 \%$ \\
& & $(1,780)$ & $(313)$ & $(405)$ & $(116)$ & $(264)$ \\
\hline Calculus A-C & 8,296 & $67.62 \%$ & $8.76 \%$ & $11.78 \%$ & $0 \%(0)$ & $11.84 \%$ \\
& & $(5,610)$ & $(727)$ & $(977)$ & & $(982)$ \\
\hline Linear Alg. & 2,040 & $70.69 \%$ & $6.85 \%$ & $8.71 \%$ & $0 \%(0)$ & $13.75 \%$ \\
& & $(1,442)$ & $(140)$ & $(178)$ & & $(280)$ \\
\hline Differential Eq. & 2,855 & $73.92 \%$ & $7.70 \%$ & $6.94 \%$ & $0 \%(0)$ & $11.44 \%$ \\
& & $(2,110)$ & $(220)$ & $(198)$ & & $(327)$ \\
\hline Computing & 2,574 & $72.96 \%$ & $5.62 \%$ & $4.22 \%$ & $6.25 \%$ & $10.95 \%$ \\
& & $(1,877)$ & $(145)$ & $(109)$ & $(161)$ & $(282)$ \\
\hline C.A.D. & 2,261 & $79.63 \%$ & $3.91 \%$ & $4.05 \%$ & $2.09 \%$ & $10.32 \%$ \\
& & $(1,801)$ & $(88)$ & $(92)$ & $(47)$ & $(233)$ \\
\hline Remedial Chem. & 3,422 & $78.83 \%$ & $6.32 \%$ & $4.45 \%$ & $5.43 \%$ & $4.98 \%$ \\
& & $(2,698)$ & $(216)$ & $(152)$ & $(186)$ & $(170)$ \\
\hline Chemistry & 6,290 & $79.59 \%$ & $7.36 \%$ & $3.47 \%$ & $3.07 \%$ & $6.51 \%$ \\
& & $(5,007)$ & $(463)$ & $(218)$ & $(193)$ & $(409)$ \\
\hline Physics I/II & 5,016 & $84.64 \%$ & $2.83 \%$ & $2.92 \%$ & $3.47 \%$ & $6.14 \%$ \\
& & $(4,246)$ & $(142)$ & $(146)$ & $(174)$ & $(308)$ \\
\hline Discipline Intro & 3,877 & $86.19 \%$ & $2.40 \%$ & $3.59 \%$ & $2.24 \%$ & $5.59 \%$ \\
& & $(3,342)$ & $(93)$ & $(139)$ & $(86)$ & $(217)$ \\
\hline
\end{tabular}

\subsection{Conclusions}

We have shown that there is a positive correlation between the numbers of course withdrawals and time to graduation and which gateway courses at UAH have high non-success rates. Some of the results from prior literature investigating the effects of demographic variables and previous academic performance have been confirmed in this analysis. However, the relationship between course withdrawals and time to graduation is sufficiently complex that there is no immediately obvious number of acceptable course withdrawals. The results indicated that withdrawing from even one course at UAH is significantly associated with an increased time to graduation. While the demographic and prior academic performance variables add to our understanding of the data, academic policies must be formulated on a consistent basis. Changes to the proposed course withdrawal policy will require additional study to examine whether a critical threshold value for the number of withdrawals can be found for particular coursework or a key level of performance. For example, the data can be further refined to test the effect of withdrawals from just calculus, from a single course, or for individuals with a continuing GPA below a minimum standard. An academic policy could be formulated to allow more withdrawal flexibility for students that have stronger academic performance. The dataset could be expanded 
to include classification of withdrawals from lower division gateway courses, upper division gateway courses, and non-gateway courses (including even non-STEM courses) to examine whether a critical threshold value could be identified from a broader perspective of course withdrawals.

We will continue to study the number of withdrawals and take the results to the Undergraduate Scholastic Affairs committee of the Faculty Senate should a recommended maximum number of withdrawals be determined. Previously, one of the authors presented analysis to the Faculty Senate that contributed to the NC grading policy being overturned. Further, we will work with the Student Success Center to offer Peer Assisted Study Sessions in the classes in which students are at the highest risk of non-success.

\section{References}

1. Olson, S. and D.G. Riordan, Engage to Excel: Producing One Million Additional College Graduates with Degrees in Science, Technology, Engineering, and Mathematics. Report to the President, in Executive Office of the President. 2012: Washington, DC.

2. Seymour, E. and N.M. Hewitt, Talking About Leaving: Why Undergraduates Leave The Sciences. 1997, Boulder, CO: Westview Press. 444.

3. Hansen, R.J., W.S. McClure, and S. Parkes, Dangerous Opportunities: Strategic Implications of the Global Financial Crisis. Continuing Higher Education Review, 2009. 73: p. 184-193.

4. Garrett, M.D. and M.C. Poock, Resource allocation and management strategies in times of fiscal constraint and their impact on students. College Student Journal, 2011. 45(4): p. 882-890.

5. Offenstein, J., C. Moore, and N. Shulock, Advancing by Degrees: A Framework for Increasing College Completion, L. Institute for Higher Education and Policy, Editors. 2010, Institute for Higher Education Leadership \& Policy and The Education Trust: Sacramento, CA.

6. Skomsvold, P., A.W. Radford, and L. Berkner, Six-Year Attainment, Persistence, Transfer, Retention, and Withdrawal Rates of Students Who Began Postsecondary Education in 2003-04. Web Tables. NCES 2011152, N.C.f.E. Statistics, Editor. 2011, National Center for Education Statistics: Washington, DC.

7. Pitter, G.W., R.E. LeMon, and C.H. Lanham, Hours to Graduation: A National Survey of Credit Hours Required for Baccalaureate Degrees. 1996, State Univ. System of Florida: Tallahassee, FL.

8. Bound, J., M.F. Lovenheim, and S. Turner, Increasing Time to Baccalaureate Degree in the United States. Education Finance and Policy, 2012. 7(4): p. 375-424.

9. Smith, G. and V. Bailey, Staying the Course. 1993, Business and Technology Education Council: London, England.

10. Friedlander, J., Why Students Drop Courses. Junior College Resource Review. 1981, Los Angeles, CA: Eric Clearinghouse for Junior Colleges.

11. Hagen, P.F. and R. Cartnal, Cuesta College Student Withdrawal Survey. 1999, Cuesta College: San Luis Obispo, CA.

12. Kangas, J., San Jose City College Withdrawing Students Study, in Research Report \#119. 1991, San Jose City College: San Jose, CA.

13. Lucas, J.A. and C. Meltesen, Study of Students Who Withdrew from Courses, Summer 1988-Spring 1990 1991, William Rainey Harper College: Palatine, IL.

14. Lucas, J.A. and C. Meltesen, Study of Students Who Withdrew from Courses, Summer 1990-Spring 1992 1993, William Rainey Harper College: Palatine, IL.

15. Hayward, C., Student Withdrawal Study. 2003, Mendocino College: Ukiah, CA.

16. Grebennikov, L. and M. Shah, Investigating attrition trends in order to improvestudent retention. Quality Assurance in Education: An International Perspective, 2012. 20(3): p. 223. 
17. Mississippi Gulf Coast Junior College, Course Withdrawal Analysis, in Institutional Research Reports No. 79/80-10 [and] 79/80-11. 1980, Mississippi Gulf Coast Community College: Perkinston, MS.

18. Sigworth, D., Student Withdrawal Study, Schoolcraft College. 1995, Schoolcraft College: Livonia, MI.

19. Nicholls, G.M., Analyzing Time to Student Course Withdrawal Patterns for Predictive Modeling, in American Society for Engineering Education Southeastern Regional Conference. 2013: Cookeville, TN.

20. Wheland, E.R., et al., What Are They Thinking? Students' Affective Reasoning and Attitudes about Course Withdrawal. NACADA Journal, 2012. 32(2): p. 17-25.

21. Chimka, J.R., T. Reed-Rhoads, and K. Barker, Proportional Hazards Models of Graduation. Journal of College Student Retention: Research, Theory \& Practice, 2008. 9(2): p. 221-232.

22. Chimka, J.R. and L.H. Lowe, Interaction and Survival Analysis of Graduation Data. Educational Research and Reviews, 2008. 3(1): p. 29-32.

23. Caroni, C., Graduation and attrition of engineering students in Greece. European Journal of Engineering Education, 2011. 36(1): p. 63-74.

24. Min, Y., et al., Nonparametric Survival Analysis of the Loss Rate of Undergraduate Engineering Students. Journal of Engineering Education, 2011. 100(2): p. 349-373.

25. Gibbings, P., et al., Part Time Study Distorts Student Attrition Rates in Engineering Programs, in Australasian Association for Engineering Education Conference. 2010, Engineers Australia: Sydney, N.S.W., Australia. p. 1.

26. Jones, S., Time Is Money... and the Enemy of College Completion: Transform American Higher Education to Boost Completion and Reduce Costs. Testimony before the United States House of Representatives Subcommittee on Higher Education and Workforce Training. 2012, Washington, DC: Complete College America.

27. Ohland, M.W., et al., Persistence, Engagement, and Migration in Engineering Programs. Journal of Engineering Education, 2008. 97(3): p. 259-278.

28. Consumer Reports, Student debt grows to alarming levels -The hundreds of billions owed have potentially crippling ramifications for the U.S. economy, in Consumer Reports. 2012, Consumer Reports: Yonkers, NY.

29. Rothstein, J. and C.E. Rouse, Constrained after college: Student loans and early-career occupational choices. Journal of Public Economics, 2011. 95: p. 149-163.

30. Federal Reserve Bank of New York, Quarterly Report on Household Debt and Credit - Q4 2013. 2014, Federal Reserve Bank of New York: New York, NY. p. 31. 